\title{
Adjustment costs in a manpower forecasting model
}

Citation for published version (APA):

van Eijs, P. W. L. J. (1994). Adjustment costs in a manpower forecasting model. Researchcentrum voor Onderwijs en Arbeidsmarkt, Faculteit der Economische Wetenschappen. ROA Research Memoranda No. 3E https://doi.org/10.26481/umaror.199403E

Document status and date:

Published: 01/01/1994

DOI:

10.26481/umaror.199403E

Document Version:

Publisher's PDF, also known as Version of record

\section{Please check the document version of this publication:}

- A submitted manuscript is the version of the article upon submission and before peer-review. There can be important differences between the submitted version and the official published version of record.

People interested in the research are advised to contact the author for the final version of the publication, or visit the DOI to the publisher's website.

- The final author version and the galley proof are versions of the publication after peer review.

- The final published version features the final layout of the paper including the volume, issue and page numbers.

Link to publication

\footnotetext{
General rights rights.

- You may freely distribute the URL identifying the publication in the public portal. please follow below link for the End User Agreement:

www.umlib.nl/taverne-license

Take down policy

If you believe that this document breaches copyright please contact us at:

repository@maastrichtuniversity.nl

providing details and we will investigate your claim.
}

Copyright and moral rights for the publications made accessible in the public portal are retained by the authors and/or other copyright owners and it is a condition of accessing publications that users recognise and abide by the legal requirements associated with these

- Users may download and print one copy of any publication from the public portal for the purpose of private study or research.

- You may not further distribute the material or use it for any profit-making activity or commercial gain

If the publication is distributed under the terms of Article $25 \mathrm{fa}$ of the Dutch Copyright Act, indicated by the "Taverne" license above, 
ADJUSTMENT COSTS

IN A MANPOWER FORECASTING MODEL

ROA-RM-1994/3E

Patrick van Eijs

RESEARCH CENTRE FOR EDUCATION AND THE LABOUR MARKET

Faculty of Economics and Business Administration

University of Limburg

Maastricht, September 1994 


\section{CIP-GEGEVENS KONINKLUKE BIBLOTHEEK, DEN HAAG}

Eijs, Patrick van

Adjustment costs in a manpower forecasting model/Patrick van Eijs.- Maastricht: Research Centre for Education and the Labour Market, Faculty of Economics and Business Administration, Rijksuniversiteit Limburg.- (ROA-RM-1994/3E)

Met lit. opg.

ISBN 90-5321-137-3

Trefw. :arbeidsmarktprognoses. 


\section{CONTENTS}

ABSTRACT

1. INTRODUCTION

2. ADJUSTMENT COSTS

2.1. Introduction

2.2. The source of adjustment costs

2.3. The structure of adjustment costs

2.4. Adjustment costs in a manpower forecasting context

3. A MANPOWER FORECASTING MODEL WITH ADJUSTMENT COSTS 12

$\begin{array}{lr}\text { 3.1. Introduction } & 12 \\ 3.2 . & 12\end{array}$

3.2. The goal of the firm 12

3.3. The production technology 12

3.4. The adjustment cost function 13

3.5. The complete model 14

4. LABOUR DEMAND UNDER STATIC EXPECTATIONS

4.1. Introduction 15

4.2. Static expectations 15

4.3. The labour demand function 16

4.4. Interpretation of the labour demand function 16

$\begin{array}{ll}\text { 5. CONCLUSIONS } & 18\end{array}$

$\begin{array}{ll}\text { REFERENCES } & 19\end{array}$

APPENDIX 1. DERIVATION OF THE LABOUR DEMAND FUNCTION UNDER STATIC EXPECTATIONS 


\section{ABSTRACT}

Manpower forecasting models often lack an economic foundation. This paper tries to overcome this drawback by introducing labour hoarding in a manpower forecasting model. The assumption is made that adjusting the educational structure of labour demand yields adjustment costs. The paper deals with three issues. In the first place, the usefulness of introducing labour hoarding in a manpower forecasting context is discussed. Secondly, a suitable specification of the adjustment cost function is presented. Finally, this function is implemented in a microeconomic model of the firm in which more types of labour are distinguished. It is shown that from this model labour demand functions can be derived in which future labour demand by type of education is a weighted mean of current demand and the long run optimal level.

I would like to thank Lex Borghans, Ron Dekker, Andries de Grip, Hans Heijke, Mieke Koeslag and Ed Willems for their helpful comments. 


\section{INTRODUCTION}

The labour market has some characteristic features. Due to the heterogeneity, the rigidities and the lack of transparency, demand and supply are rarely in alignment with each other. As a result, mismatch phenomena occur frequently. In other words: the agents' labour market position often falls short of their expectations. It is not surprising that much attention has been paid to instruments that can contribute to the avoidance of these mismatches. One of these instruments is manpower forecasting. Manpower forecasting deals with projecting the labour demand and supply, especially the occupational and educational structure of demand and supply. Manpower forecasting has an information and a policy function nowadays. That is, its purpose is to give insight into the future developments in the labour market, which enables participants to make necessary adjustments to the changing situation in time and being an instrument for educational policy makers (see Van Eijs, 1994).

Unfortunately, today's manpower forecasting models for a great deal lack an economic foundation. Current manpower forecasting practice heavily relies on trend extrapolation methods for reasons of simplicity and data limitations. ${ }^{1}$ However, trend extrapolation techniques have two important drawbacks (see Van Eijs, 1994). In the first place, these techniques do not give insight into the factors causing occupational and educational shifts. In the second place, the past data are used in a wrong way. Past data do not reflect labour demand but market outcomes when interactions between demand and supply have occurred.

An important issue related to finding an economic foundation for manpower forecasts is the interaction between demand and supply. Because the supply side can be characterised by means of types of education and because wages seem to be primarily linked with (required and possessed) types of education (see, for example, Van Ophem and Hartog, 1993), the interaction between demand and supply can be supposed to take place on the educational level. On the one hand the demand side first determines his labour needs in terms of occupations. Subsequently, these occupational needs are translated into educational needs. On the other hand, on the supply side students make educational choices. If a gap between demand and supply occurs on a particular educational submarket, the market can reply to this gap by means of shifts in demand and supply as a result of, for example, wage adjustments.

From a theoretical point of view, four types of models are required in order to describe such an interaction process between demand and supply on an educational submarket:

1. an ex ante supply model, describing how the educational structure of labour supply depends on a students' expectations on wages, career possibilities, etc..

2. an ex ante demand model, describing how the educational structure of labour demand depends on a firm's expectations with regard to wages, output, technological progress, etc..

3. a (partial) interaction model, describing how the demand and the supply side react on gaps between ex ante demand and ex ante supply.

4. a multi-market spillover model, describing how ex ante gaps on other educational submarkets have an impact on a particular submarket.

By means of these models both ex ante and ex post gaps can be provided for every submarket (type of education). From the students' point of view, ex ante gaps indicate the probability to get the perfect job. From the employers' point of view, these gaps indicate the probability to get the perfect worker. The

1. For an overview of current manpower forecasting practice, see, for example, Hughes (1993) and Heijke (1994). Van Eijs (1994) discusses the forecasting methodology of a number of important Western institutes. 
larger the ex ante gap, the more mismatch occurs on this submarket. Mismatches may have several consequences: wage adjustments, choosing an imperfect job or worker, unemployment or vacancies that cannot be fulfilled. Ex post gaps indicate the probability to get unemployed, respectively the probability that vacancies cannot be fulfilled. The difference between ex ante and ex post gaps indicate the number of imperfect matches. ${ }^{2}$ Of course, the picture drawn above reflects an utopian view on manpower forecasting. Due to the danger of analytical complexity and data limitations, this is an unattainable ideal. Simplifications have to be made.

In this paper, an ex ante demand model is developed. Starting-point is the empirical finding that the educational structure of labour demand does not change quickly (see Nickell, 1986). For underpinning this finding, the labour hoarding literature may be useful. Labour hoarding occurs if firms do not adjust their labour demand for changing conditions. Several reasons can be given for labour hoarding (see, for example, De Koning, 1987). A lot of reasons can be summarised by stating that adjusting the size of labour demand yields adjustment costs. This kind of analysis can also be applied to the educational structure of labour demand. The fact that firms do not adjust the educational structure quickly and that habit formation plays an important role in the decision process can be underpinned analytically by assuming that both adjusting the size of a firm's staff and altering the educational composition of the staff is costly. Hiring and firing workers result into so-called adjustment costs. This implies that profit maximising firms do not follow changing market conditions completely.

The model developed in this paper is based on Gould (1968) and Nadiri and Rosen (1973). Gould (1968) shows that, if a firm has static expectations and has to cope with convex capital adjustments costs, the future size of the capital stock $K_{t+1}$ is a weighted mean of the current stock $K_{t}$ and the profit maximizing stock in the case of zero adjustments costs $K^{*}$ :

$$
K_{t+1}=\delta K^{*}+(1-\delta) K_{t}
$$

Gould's model has also been applied in a labour demand context, for example by Nickell (1986). He considered labour to be a homogeneous factor. In order to use for manpower forecasting purposes, a model is required in which labour is considered to be heterogeneous, however. Nadiri and Rosen (1973) describe a model which meets this requirement. Their multi-factor model results into the following factor demand equation:

$$
Z_{q, t+1}=\Psi_{q q} Z_{q, t}+\sum_{r \neq q} \Psi_{q} Z_{r, t}+\sum_{s} \omega_{q, s} X_{s, t+1}
$$

in which $Z_{q, t}$ is the demand for production factor $q$ in period $t$, the $\Psi_{q r}$ are the adjustment parameters and $X_{s}$ is an exogenous variable determining the profit-maximizing stock of production factor $q$ in the case of zero adjustment costs $Z_{q, t+1}^{*}$ :

$$
Z_{q, i+1}^{*}=\sum_{s} \omega_{q s} X_{s, i+1}
$$

In this paper, Gould's and Nadiri's and Rosen's models are applied in a manpower forecasting context. The firm's decision process with regard to the educational composition of the staff is described.

It should be noted that this paper is purely theoretical. The emphasis is on making an adjustment cost model suitable for manpower forecasting purposes. The theoretical model developed in this paper is not tested empirically. In a subsequent paper attention will be paid to adjusting the theoretical model in order to make it testable and to investigating the reliability of the model. 
$-3-$

The structure of the remainder of this paper is as follows. Section 2 gives a brief overview of labour adjustment cost literature. Furthermore, it tries to link this literature with manpower forecasting. In that way, it provides a foundation for some of the assumptions made in the model later on. Section 3 describes the model. Attention is paid to the assumptions made and the specification of the functions used. In section 4 the model is solved. It is shown that future labour demand by type of education in a particular occupation within a particular industry is a weighted mean of current demand and the long-run profit maximising demand. Finally, in section 5 some concluding remarks are made. 


\section{ADJUSTMENT COSTS}

\subsection{Introduction}

In principle, a firm facing changing circumstances may behave in three ways with regard to labour demand (see Nadiri and Rosen, 1973):

1. adjusting labour demand continuously and avoiding inventories of output;

2. keeping labour demand and output constant and holding inventories of output;

3. taking a position in between these two extremes;

The first strategy is rarely used in practice. In other words: labour hoarding is an important phenomenon on the labour market. Labour demand is very stable during time. On the one hand, this phenomenon is caused by the fact that the determinants of labour demand do not change quickly. On the other hand, however, labour demand is more stable than by reason of developments in these determinants might be expected (see Nickell, 1986).

In economic research it has been tried to find ways to rationalise this kind of behaviour. The existence of adjustment costs is introduced in labour market theory dealing with habit formation and labour hoarding by Holt et al. (1960) and Oi (1962). Furthermore, by means of introducing adjustment costs dynamic elements are introduced in (static) labour demand theory. This section deals with two issues in adjustment cost literature. In the first place, it deals with the source of adjustment costs. In other words, which factors cause adjustment costs. Secondly, attention is paid to the structure of adjustment costs. In other words, in which way are the costs related to the size of the adjustments. Both theoretical and empirical aspects are discussed. ${ }^{3}$ Unfortunately, in adjustment cost literature labour is treated on a highly aggregated level. Therefore, attention has to be paid to the relevance of adjustment cost theory in a manpower forecasting context. The emphasis is on the source and the structure of adjustment costs again.

\subsection{The source of adjustment costs}

Not surprisingly, adjusting the work force in a firm is costly and results into costs over and above the wage payments. Hiring workers results for example into advertising, testing and training costs. Firing workers results for example into the payment of unemployment benefits and outplacement costs. Not only hiring and firing workers result into costs. Simply adjusting the size of the work force is costly also. For example, increasing or decreasing the employment level results into reorganization costs. Therefore, often a distinction is made between gross and net adjustment costs. Net costs are linked with adjustments in the size of the work force. Gross costs are linked with hiring and firing workers. To state it in another way, net costs are linked with (the number of) jobs. Gross costs, on the other hand, can be viewed to be linked with the individual person being hired or fired (see Hamermesh, 1993b). ${ }^{4}$ Unfortunately, empirical studies dealing with the source of adjustment costs are rare. Hamermesh (1993b) uses data on hospitals to conclude that both net and gross costs are important. The emphasis is on gross costs, however.

Furthermore, a distinction can be made between internal and external adjustment costs. The external

3. In this paper only a few aspects of the adjustment cost literature are discussed. For a more extensive overview of this literature, see, for example, Nickell (1986) and Hamermesh (1993a).

4. To be precise, also a distinction has to be made between employment in hours and employment in number of workers. However, in the remainder of this paper it is assumed that the number of hours a person is employed is fixed. 
costs are those discussed above. These costs are not linked with the production process and do not reveal in the production function. In other words, these costs reveal explicitly in the cost function. Internal costs, on the other hand, have an impact on the production process. These costs are inherent in the production function (see Hamermesh, 1993a). In other words, these costs do not reveal explicitly in the cost function, but have an impact on the (marginal) productivity of labour. For example, suppose the larger the number of new employees to be hired, the smaller the average quality of these new employees may be. This implies that, the larger the number of new employees, the larger the internal adjustment costs.

\subsection{The structure of adjustment costs}

The source of the adjustment costs is one part of the story. The other part is the structure. In other words, which link occurs between adjustments and costs? In adjustment cost literature very often a quadratic symmetric function is used:

$$
A C=a|\dot{L}|+b L^{2} \quad a, b>0
$$

in which $A C$ is the size of the adjustment costs and $L$ the size of the adjustment in labour demand $(i=\delta L \delta t)$. This is a very attractive specification because of its simplicity and analytical workability. But, at the same time, its simplicity is an important weakness. This adjustment cost function has three important drawbacks. In the first place, it is strictly convex, like curve $A$ in figure 2.1 :

Figure 2.1 A convex and a nonconvex adjustment cost function

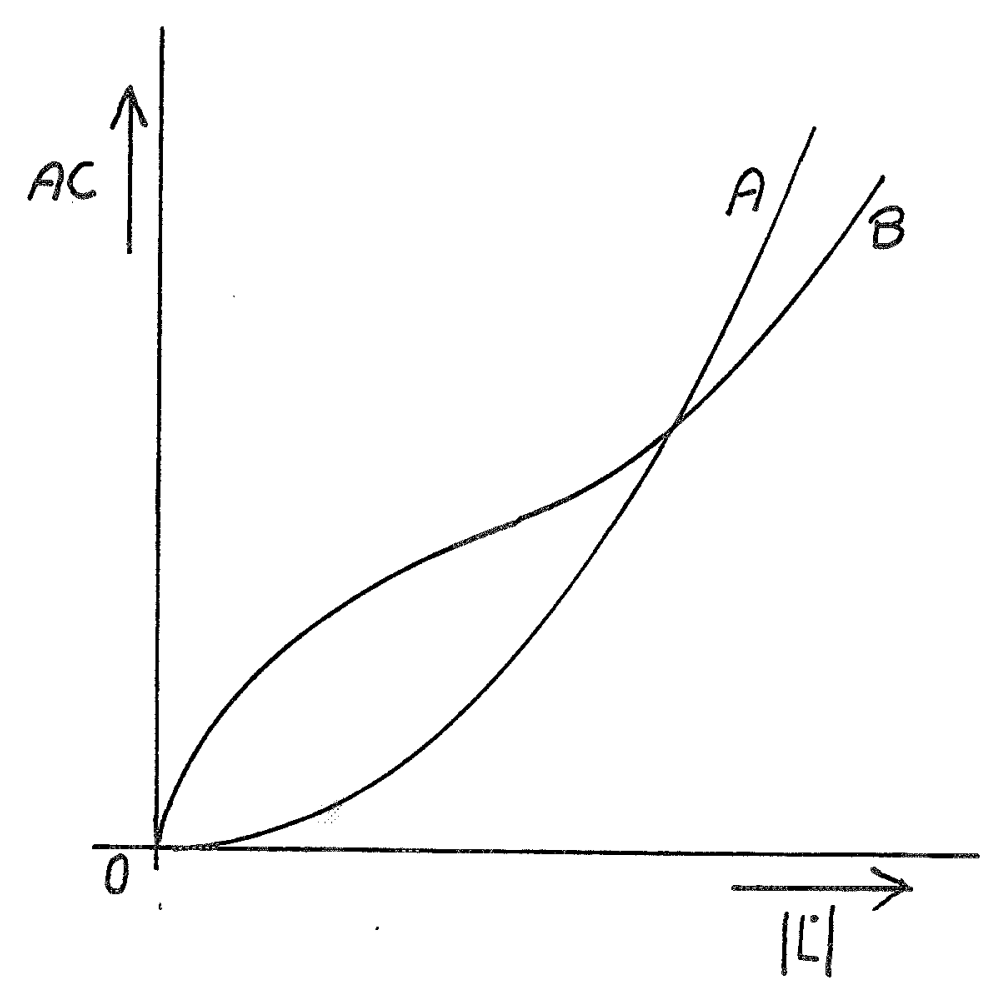


Nickell (1986) makes clear that it is more reasonable to assume that both hiring and firing costs are concave for small adjustments, like curve $B$ in figure 2.1. However, strict convexity is a very convenient assumption in dynamic theory for analytical purposes. ${ }^{5}$ It should be noted that, because strict convexity is considered to be the best option, no attention is paid here to lumpy adjustment cost models like in Hamermesh (1993b). A second feature of the cost function described by equation (2.1) is its symmetry. This implies that hiring and firing yield the same costs, which is a rather restrictive assumption. In the third place, it is reasonable to assume that voluntary quits yield much less costs than firing workers. This implies that by using this function it is implicitly assumed that there are only net adjustment costs, unless there are no voluntary quits.

Pfann (1990) has used a function which meets the second and the third drawback. The advantage of this function is its flexibility. It is able to take different shapes. It looks as follows:

$$
A C=-a \dot{L}+b L^{2}+\exp (a \dot{L}) \quad a, b>0
$$

Unless $a=0$, this function is asymmetric. If $a>0$, hiring costs exceed firing costs. If $a<0$, firing workers is more expensive then hiring them. In this function a distinction is made between situations in which hiring exceeds firing, which implies that labour demand rises and situations in which labour demand falls. This implies that both net and gross costs are implicitly taken into account.

The approach chosen by Gould (1968) overcomes the drawbacks of the symmetric quadratic function partly. As already mentioned in the introduction, applying Gould's model in a labour market context implies that future labour demand is a weighted mean of current demand and the long-run optimum. To achieve this result, Gould uses the following adjustment cost function:

$$
A C=a(L+\delta L)^{2} \quad a>0
$$

in which $\delta$ is the voluntary quit rate, which is assumed to be constant. This is a symmetric gross adjustment costs function. It is a gross function, because a distinction is made between voluntary and involuntary quits. On the other hand, the function is symmetric; hiring and firing (that is, an involuntary quit) yield the same costs.

Testing equation (2.2) yields a mixed picture. (see Pfann, 1990). In some cases, hiring costs exceed firing costs. In other cases the opposite picture occurs. In other words, on beforehand it is difficult to draw conclusions with regard to the skewness of the adjustment cost function. Therefore, it seems to be acceptable to use Gould's symmetric approach, which is much easier to deal with from an analytical point of view. However, equation (2.3) is an aggregated function in which labour is treated to be homogeneous. Section 2.4 deals with using adjustment cost theory in general and Gould's contribution in particular in a manpower forecasting context.

\subsection{Adjustment costs in a manpower forecasting context}

Adjustment cost literature often is applied on a high aggregation level. At most two types of labour are distinguished. Pfann (1990), for example, makes a distinction between production and nonproduction workers. Other comparable examples are blue and white collar and skilled and unskilled workers (see Nickell, 1986). ${ }^{6}$ Furthermore, adjustment cost literature deals with adjustments in the size of the work force. Because of these characteristics, existing adjustment cost theory can not be simply applied in a manpower forecasting context. In the first place, manpower forecasting by definition deals with labour

5. See, for more details, Pfann (1990).

6. It should be noted here that these distinctions can be considered to be more or less analogous. 
demand on a low aggregation level. Its aim is to forecast the occupational or educational structure of labour demand. Furthermore, in manpower forecasting practice total employment (by industry) is given by means of macroeconomic forecasts used as a starting point for the analysis (see Van Eijs, 1994). In fact, manpower forecasting deals with forecasting shares of occupations and types of education in total industrial labour demand. This subsection deals with three questions. In the first place, how can the introduction of adjustment cost theory in manpower forecasting be underpinned? Secondly, which impact does this introduction have on aspects like the source and the structure of adjustment costs? Finally, which conclusions can be drawn with regard to the characteristics of an adjustment cost function in a manpower forecasting context?

As mentioned above, manpower analysis deals with forecasting the occupational and educational structure of labour demand. Total employment is given. Therefore, if adjustment cost theory is applied in a manpower forecasting context, these costs should be interpreted as the costs of changing the composition of the work force. ${ }^{7}$ Changing the occupational composition may be seen as changing the organisational structure of a firm, which may, for example, yield costs linked with reorganisation. Changing the educational structure of the workforce within an occupational group may be interpreted as changing the contents of occupations and thereby changing the skill requirements for those working in these occupations (see Van Eijs and Borghans, 1993), which may yield costs linked with training and reorganisation.

However, from an analytical point of view, it is easier to deal with allocating adjustments costs to the 'adjustment levels'. The considerations made above are not needed. Given the fact that industrial employment is an exogenous variable in manpower forecasting, labour demand for type education $i$ in occupation $j$ in industry $k$ can be considered to be composed of several elements:

$$
L_{i j k}=\left(\frac{L_{j k}}{L_{k}}\right)\left(\frac{L_{j k}}{L_{j k}}\right) L_{k}
$$

The following equation can be derived from equation (2.4):

$$
L_{i j, t+1}=\left(l_{j, t}+\Delta I_{j k}\right)\left(l_{j, t^{\prime},}+\Delta I_{j k}\right)\left(L_{k, t}+\Delta L_{k}\right)
$$

in which:

$$
I_{j k}=\frac{L_{j k}}{L_{k}}
$$

and

$$
I_{\text {isk }}=\frac{L_{j j k}}{L_{j k}}
$$

Furthermore, for a particular variable $V, \Delta V$ is defined as:

$$
\Delta V=V_{t+1}-V_{t}
$$

7. It should be noted, that this does not exclude the possibility that adjusting total employment yields costs too. 
Equation (2.5) can be rewritten as:

$$
\begin{aligned}
L_{j k, t+1} & =l_{j k, t} * l_{j k, t} * L_{k, t}+l_{j k, t} * l_{i j k, t} * \Delta L_{k} \\
& +\Delta l_{j k k} * l_{j k, t} * L_{k, t}+l_{j k, t} * \Delta l_{j j k} * L_{k, t} \\
& +\Delta l_{j k} * l_{j k, t} * \Delta L_{k}+l_{j k, t} * \Delta l_{j k} * \Delta L_{k} \\
& +\Delta l_{j k} * \Delta l_{j j k} * L_{k, t}+\Delta l_{j k} * \Delta l_{j j k} * \Delta L_{k}
\end{aligned}
$$

Equation (2.6) shows that, besides four interaction effects, future labour demand $L_{i j k, t+1}$ consists of four elements. The first element is current labour demand $L_{i j k, t} .{ }^{8}$

$$
L_{j i k, t}=I_{j k, t} I_{j k, t} * L_{k, t}
$$

Secondly, the change in labour demand as a result of a change in industrial employment $L_{k}$. This is called the fixed coefficient effect $F C_{i j k}$ :

$$
F C_{i j k}=l_{j k, *} * l_{i j k, t} * \Delta L_{k}
$$

The occupational effect $O C_{i j k}$ is the third element. It reflects the change in labour demand for type of education $i$ in occupation $j$ in industry $k$ as a result of a change in the occupational structure:

$$
O C_{j k}=\Delta I_{j k} * I_{i j, t} * L_{k, t}
$$

In the fourth place, the educational effect EDUC result of a change in the educational structure within occupations:

$$
E D U C_{i j k}=l_{j k, t} * \Delta I_{j i k} * L_{k, t}
$$

So, equation (2.6) shows that the change in labour demand for type of education $i$ in occupation $j$ in industry $k L_{i j k, t+1}-L_{i j k, t}$ can be divided into three elements: a fixed coefficient effect, an occupational effect and an educational effect. This implies that, from an analytical point of view, demand adjustments can be allocated to these effects. As a result, adjustment costs can also be allocated to these effects.

In this paper, adjustment costs are introduced in a model in which the educational structure within occupations is forecast. In other words, it deals with forecasting $E D U C_{\text {lik }}$. Employment by occupation is supposed to be given. ${ }^{9}$ What is the impact of adjustment costs in such a model? Suppose the way in which workers, having different qualifications (types of education), contribute in occupational activities can be reflected by an occupational production function. ${ }^{10}$ Suppose further that this 'occupational production function' yields convex 'isoquants'. If it is assumed that there are two types of education, figure 2.2 shows the decision process of the firm:

8. Note that equation (2.7a) is equivalent to equation (2.4).

9. It should be noted that a similar model can be developed to describe the occupational effect $O C_{i j k}$. This may be very useful, because reorganisations within firms often result in changes in the occupational structure.

10. For more details, see section 3. 
Figure 2.2 A firm's behaviour with regard to labour demand by type of education in the case of adjustment costs

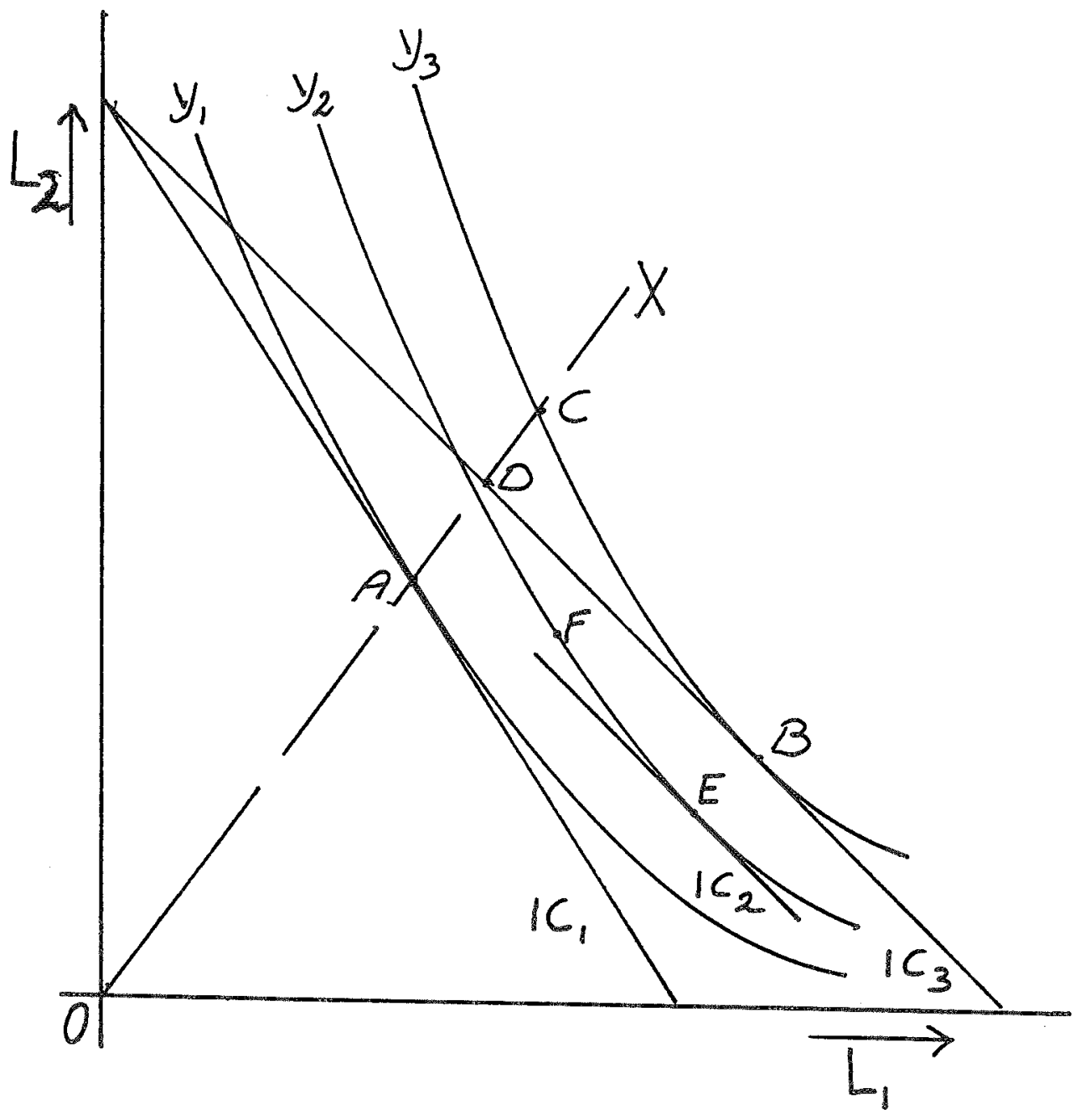

Suppose $A$ is the original optimum describing the optimal composition of labour demand by type of education. The 'isocost line' $I C_{1}$, of which the slope reflects the ratio of the wages, is tangent to the 'isoquant' $y_{1} .{ }^{11}$ Now, type of education 1 becomes more attractive for firms, for example because the wage paid to people having this type of education decreases. The new long-run optimum is $B$ where the 'isocost line' $I C_{2}$ is tangent to the isoquant $y_{2}$. The fact that type of education 1 becomes more attractive has both an occupational (from $A$ to $C$ ) and an educational effect (from $C$ to $B$ ). However, due to the fact that both adjusting the occupational and the educational composition of the work force yield (external) costs, the long-run optimum $B$ will never be achieved. Both the occupational and the educational effect occur partly. First, the firm moves to a point between $A$ and $C$, for example $D$. In $D$ the shares of both types of education in total employment are equal to those in $A$; both $A$ and $D$ are on $O X$. Moving to $D$

11. Note that the adjustment costs are not taken into account in the 'isocost line' . If the adjustment cots would be taken into account, the shape of the isocost function depends on the structure of the adjustment costs and on the 'point of departure' $A$. 
implies that the new optimum becomes $E$ where $I C_{3}$ is tangent to $y_{3}$. Due to the costs of adjusting the educational structure within an occupation, $E$ is not achieved either. The firm chooses a point somewhere in between $D$ and $E$ on $y_{3}$, for example $F$. To summarise, given the fact that adjustment costs are moderate, the firm chooses a point somewhere in between $A$ and $B$, instead of the long-run optimum $B$.

Attention should also be paid to the distinction between net and gross costs on the one hand and internal and external costs on the other. In a manpower forecasting context the distinction between net and gross costs seems to be problematic. The problem is, how should net costs be interpreted? The lower the aggregation level, the more adjustments costs are linked with individuals. In other words, the lower the aggregation level, the more the emphasis is on gross costs.

The distinction between internal and external costs, on the other hand, can also be made in this manpower forecasting context. Examples of external costs are given above. Internal costs include, for example, the loss in productivity because workers have to settle in their new job and the loss in production because reorganisations take time. However, in the remainder of this paper, these costs are ignored, because it is very difficult to model and to quantify them. Ignoring internal costs implies, for example, that the type of education is assumed to be the only factor on which workers differ.

By definition, manpower forecasting deals with heterogenous labour. Making a distinction between production factors in general or types of labour in particular in an adjustment cost model raises several problems. In order to clarify these problems, it is useful here to repeat the labour demand function of Nadiri's and Rosen's multi-factor model:

in which:

$$
Z_{q, t+1}=\Psi_{q q} Z_{q, t}+\sum_{r+q} \Psi_{q} Z_{r, t}+\sum_{s} \omega_{q s} X_{s, t+1}
$$

$$
Z_{q, t+1}^{*}=\sum_{s} \omega_{q s} X_{s, t+1}
$$

The crucial parameters are the $\Psi_{g r}$ 's. These spillover parameters indicate the impact of gaps between the long run level and the actual level of the demand for other factors (types of labour) on the speed of adjustment of the demand for factor (type of labour) $q$. If $\Psi_{\phi}>0$, a larger gap for factor $r$ slows adjustments in demand for factor $q .{ }^{12}$ If $\Psi_{q}<0$, a larger gap for factor $r$ results into faster adjustments in demand for factor $q .^{13}$

With regard to the structure of the adjustment cost function in a manpower forecasting context, several useful characteristics of such a function can be given. In the first place, the function should be convex. A lumpy cost function does not seem to be useful. Such a model results into rather drastic adjustments (see Hamermesh, 1993b). However, in a multi-firm context like in manpower forecasting, adjustments are rather smooth. From a theoretical point of view, a (partly) concave function might be preferable, but for analytical convenience such a function is not chosen. Secondly, the structure should be consistent with an emphasis on gross costs. Thirdly, internal adjustment costs are not introduced, because these costs are difficult to model and to quantify. Finally, attention should be paid to the spillover parameters. On a low aggregation level, introducing these parameters in a manpower forecasting model with adjustment costs would be very difficult, because it would result into a very large amount of variables in the model. Estimating these parameters would be an almost impossible task. If, as in the ROA information system on education and the labour market, 54 types of education are distinguished, this would imply that, within

12. Then the factors $q$ and $r$ are called $p$-complements.

13. Then the factors $q$ and $r$ are called $p$-substitutes. 
an occupation, 1431 parameters should be estimated. ${ }^{14}$ Therefore, restrictive assumptions have to be made. Unfortunately, no theoretical or empirical evidence can be given on the size or even of the sign of the spillover-parameters. Therefore, these effects are not taken into account.

In section 3 the manpower forecasting model in which adjustment costs are introduced is described. So, attention is also paid to the adjustment cost function which meets the characteristics mentioned above.

14. If 54 types are distinquished, then the number of parameters is $54 * 53 / 2=1431$. 


\section{A MANPOWER FORECASTING MODEL WITH ADJUSTMENT COSTS}

\subsection{Introduction}

Section 2 paid attention to the relevance and the interpretation of adjustment costs in a manpower forecasting context. In this section an ex ante labour demand model with adjustment costs is described. In the first place, the goal of the firm is discussed. Secondly, attention is paid to the production technology. Subsequently, the adjustment cost function, which is the new element in this manpower forecasting model, is discussed.

\subsection{The goal of the firm}

The model described here is a labour demand model. This implies that the behaviour of the firm should play a central role. Suppose every industry consists of one representative profit-maximising firm. ${ }^{15}$ Assume further that this firm is price taker on all the markets in which it is involved: the commodity market and the factor markets. As already mentioned above, introducing adjustment costs implies that the firm's decision process becomes intertemporal. In other words, the firm does not aim to maximise current profit $\pi_{0}$, but tries to maximise a flow of current and (discounted) future profits $\pi_{0}^{*}$ :

$$
\pi_{0}^{*}=\int_{t=0}^{\infty} \pi_{t} e^{-r t} d t
$$

in which $r$ is the discount rate. In this intertemporal profit function $\pi_{t}$ can be defined as:

$$
\begin{aligned}
\pi_{t}= & P_{t} Y_{i}\left(Z_{1,}, Z_{2 p} Z_{3 p} \ldots, Z_{n t}\right)-\sum_{i=1}^{n} w_{i} Z_{i t} \\
& -A C\left(\dot{Z}_{1 p} \dot{Z}_{2 p} \dot{Z}_{3 i} \ldots, \dot{Z}_{n t}\right)
\end{aligned}
$$

in which $P_{t}$ is the product price at time $t, Y_{t}$ is the output, $Z_{i}$ is the demand for production factor $i, w_{l}$ is the price of production factor $i$ and $A C$ are the adjustment costs.

\subsection{The production technology}

As already mentioned above, the assumption is made that a firm first determines its occupational needs. Subsequently these occupational needs are translated into educational needs. This assumption is reflected in the production technology described here. ${ }^{16}$ The technology in an industry $k$ can be described by the following Cobb-Douglas production function:

$$
Y_{k}=v_{k}\left(C_{k}\right)^{\alpha_{k}} \prod_{j}\left(y_{j k}\right)^{\beta_{k x}}
$$

There are $m+1$ 'production faciors': capital $(C)$ and $m$ occupational activities $j$. Equation (3.3) shows that these activities contribute $y_{j k}$ to the total production $Y_{k}$. $y_{j k}$ is produced by workers who can be characterised by their qualifications (type of education $i$ ). In a manpower forecasting context this is a reasonable assumption. In presenting manpower forecasts the individual characteristics of a student can not be taken into account. In other words, manpower forecasts describe the labour market position of the 'mean' student. It is assumed that education is the only factor determining an individual's qualifications.

15. This assumption is not very restictive. It can be shown that if firms have the same technology, which is described below, aggregation of these firms results in a similar production technology. Furthermore, it has to be assumed that firms face the same adjustment costs.

16. This specification of the production technology is also used in Van Eijs and Borghans (1993), in which more details can be found. 
The Cobb-Douglas 'occupational production function' describing the occupational activities looks as follows:

$$
y_{j k}=\mu_{j k} \prod_{i}\left(L_{i j k}\right)^{y_{j k}}
$$

in which $L_{i j k}$ is the number of workers having qualifications $i$ employed in occupational activity $j$ in industry $k$. It is assumed that there are no hours-workers substitution possibilities. The working time by worker is constant.

The distinction between two production functions (3.3) and (3.4) seems to be artificial. However, it can be shown that this specification of the production process implies that the underlying decision making process consists of two independent stages. This feature, which is called separability, is very useful here, because the other decision variables, like $C_{k}$ and $L_{j k}$ can be assumed to be predetermined when decisions are taken with regard to the educational needs.

In this paper, two additional assumptions with regard to the production technology are made. In the first place, for analytical reasons, it is assumed that the occupational production function (3.4) is homogeneous of degree 1. This seems to be a very restrictive assumption. However, if the optimal size of the firm is achieved in the long run, there are no economies of scale anymore, which is exactly one of the features of a linear homogeneous production iunction. If the production function described by equation (3.4) is linear homogeneous, it can be written as:

$$
y_{j k}=\mu_{j k} \prod\left(l_{j k}\right)^{\gamma} L_{j k}
$$

in which:

$$
I_{i j k}=\frac{L_{i j k}}{L_{j k}}
$$

Equation (3.4') fits perfectly in a manpower forecasting framework. Given the occupational needs $L_{j k}$ in an industry $k$, the educational needs within this occupation are determined by equation (3.4').

Secondly, given the 'occupational production' $y_{j k}$, it is assumed that employment within occupation $j$ can be obtained by means of a fixed coefficient function:

$$
L_{k k}=c_{j k} y_{j k}
$$

\subsection{The adjustment cost function}

In section 2 attention was paid to the characteristics of an adjustment cost function in a manpower forecasting context. In this paper the following function is chosen to describe the costs associated with adjusting the educational structure of labour demand within occupations:

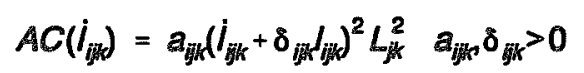

in which $i_{j k j}=\partial l_{g k t} / \partial t, a_{j k}$ is a parameter determining the size of the adjustment costs and $\delta_{j k}$ is the voluntary quit rate. This is a variant of the function used in Gould (1968). The amount of the production factor is replaced by the share of a type of education in occupational labour demand in an industry. The characteristics mentioned in section 2 can be found in this function. In the first place, the function is convex in $i_{j k}$. Secondly, the function is symmetric. These are rather restrictive assumptions. In a manpower forecasting context, however, the emphasis is not on the exact structure of the adjustment cost function, but on the implications of introducing such costs in a manpower forecasting model. Therefore, for analytical convenience, the function is assumed to be convex and symmetric. In the third 
place, it is a gross function. The size of the adjustment costs depends on the current employment share of workers with a particular educational background. Finally, spillover effects between types of education with regard to the adjustment costs are not taken into account.

\subsection{The complete model}

To summarise, the model describing a firm's decisions with regard to the educational structure of labour demand looks as follows. The firm's decisions are made in a two-stage procedure. In the first stage, the contribution of every occupation to total output is determined. This stage is not investigated in the model described here; the occupational contributions $y_{j k}$ are supposed to be given. The model deals with explaining the educational structure within occupations. Firms aim to maximise the flow of future (discounted) profits:

in which:

$$
\pi_{j k, 0}^{*}=\int_{t=0}^{\infty} \pi_{j k, t} e^{-\pi t} d t
$$

$$
\begin{aligned}
& \pi_{j k, t}=\lambda_{j k,} y_{j k,}\left(L_{1 j k, n} L_{2 j k, n} L_{3 j k, \beta} \cdots, L_{n j k, t}\right)-\sum_{i=1}^{n} w_{i, 1} L_{i j, t} \\
& \text { - } A C\left(i_{1 j k, B} i_{2 j k, n} i_{3 j k, \ldots, \ldots,} i_{n j k, t}\right.
\end{aligned}
$$

in which $\lambda_{j k}$ is the shadow price of a unit of occupational output $y_{j k}$. In equation (3.2') the equations (3.4') and (3.5') can be substituted:

$$
y_{j k, t}=\mu_{j k} \prod_{i}\left(l_{j k x, t}\right)^{\gamma_{k r} L_{j k, t}}
$$

and:

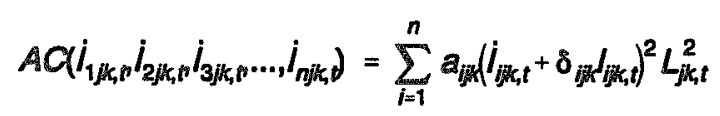

In section 4 this model will be solved under the assumption that firms have static expectations with regard to wages and prices. The result is a labour demand function determining $I_{\text {牧, }}$, the share of type of education $i$ in occupational employment $j$ in industry $k$. 


\section{LABOUR DEMAND UNDER STATIC EXPECTATIONS}

\subsection{Introduction}

In section 3 a model explaining the educational structure of labour demand is described. In this section a solution under static expectations is given for this model. In the first place, the assumption that expectations are static is discussed. Secondly, the solution is derived. In other words, the labour demand function is derived. Finally, an interpretation of this solution is given.

\subsection{Static expectations}

Equation (3.2') shows that firms maximise the flow of (discounted) future profits. This implies that firms have to form expectations with regard to the developments in the environment of the firm. From an analytical point of view, this implies that a firm has to form expectations with regard to the future time path of the exogenous variables. In this model, there are two types of exogenous variables. In the first place, wages, product prices and interest rates. Firms are assumed to be operating on competitive markets; they are not able to change prices, wages and interest rates on their own. In the second place, technological developments, which are reflected by the production functions. It is assumed that decisions with regard to changing the production process do not have an impact on decisions with regard to the educational structure of labour demand. ${ }^{17}$

In this paper the assumption is made that firms have static expectations. In other words, firms expect wages, prices, interest rates and technological parameters to be constant over time. This is a rather restrictive assumption. Firms do not expect the exogenous variables to fluctuate or to show a trend in the future, but expect them to be on a constant level. However, for several reasons this assumption is not so restrictive as it seems in a manpower forecasting context. In the first place, suppose medium term manpower forecasts are made, that is about five years. This implies that, from a manpower forecasting point of view, only five years are relevant. Expecting that the exogenous variables are constant over the next five years is a much less restrictive assumption then assuming that these variables are constant over the whole time horizon. It can be assumed that firms may adjust their expectations every five years. ${ }^{18}$ In the second place, relative prices and wages play an important role. The general level is not important, because total industrial employment is already given. Assuming that, for example, the wage structure does not change seems not to be as restrictive as assuming that the (absolute) wage level does not change.

17. Furthermore, the assumption is made that the adjustment cost function does not change over time.

18. It should be noted that one important aspect is not taken into account here. The fact that firms expect the exogenous variables to be constant for more than five years has also an impact on current decisions. 


\subsection{The labour demand function}

Given the assumption that firms have static expectations, the model of section 3 can be solved. The solution which is derived is the labour demand function for the share of type of education $i$ in employment in occupation $j$ and industry $k$. The following time path can be derived: ${ }^{19}$

$$
i_{i j k}=\delta_{i j k}\left(I_{j k k}^{*}-I_{i j k}\right)
$$

In this equation $l_{i j k}^{*}$ can be found. This is the long run optimum level of the share under consideration. The continuous equation (4.1) can be transformed to obtain the result for the development in a discrete time period:

$$
\Delta I_{i k, t}=\delta_{i j k}\left(l_{i j k}^{*}-I_{i j k, t}\right)
$$

From equation (4.1') the future share of type of education $i$ in employment in occupation $j$ and industry $k$ can be derived:

$$
l_{i j k, t+1}=\delta_{i j k} l_{i j k}^{*}+\left(1-\delta_{i j k}\right) I_{i j k, t}
$$

It can be shown that, given the assumptions made in this paper, the optimal share $I_{\text {fok }}^{*}$ is equal to: $:^{20}$

$$
I_{j k k}^{*}=\frac{\lambda_{j k} \gamma_{i j k} \theta_{i j k}-w_{i}}{2 a_{i j k} \delta_{j k h}\left(r+\delta_{j k k} L_{j k}\right.}
$$

in which $\theta_{j k}$ is a technological parameter linked with the assumption made in equation (3.5). In section 4.4, attention is paid to the interpretation of the equations (4.1") and (4.2).

\subsection{Interpretation of the labour demand function}

Equation (4.1") shows that the existence of adjustment costs can rationalise labour hoarding and habit formation. Adjustments in the educational structure pass slowly. The current structure plays an important role in determining the future structure. The nature of the adjustment costs may indicate how the phenomenon described by equation (4.1") may be interpreted. If the adjustment costs are material, it may be seen as labour hoarding. If, however, the adjustment costs are immaterial, the term habit formation seems to be more useful.

It should be noted that the voluntary quit rate $\delta_{j k}$ plays an important role in equation (4.1"). The higher this rate, the faster the educational structure is adjusted. The distinction between material and immaterial costs can also be made here. If the voluntary quit rate is high, labour hoarding is a less important phenomenon, because voluntary quits do not result into firing costs. It also seems reasonable to assurne that the immaterial costs accompanied with voluntary quits are lower that the costs accompanied with involuntary layoffs.

19. The derivation of this equation can be found in appendix 1 .

20. The derivation of this equation can also be found in appendix 1 . 
Equation (4.2) gives an expression for the long run equilibrium value for the share of type of education $i$ in occupation $j$ in industry $k l_{j k}^{*}$. Here the assumption that expectations are static plays an important role. Equation (4.2) can be rearranged to obtain three parts:

$$
l_{i j k}^{*}=\left(\frac{1}{\left.2 a_{j k} \delta_{j k k} r+\delta_{j k k}\right)}\right)\left(\lambda_{j k} \gamma_{j j k} \theta_{i j k}-w_{i}\right)\left(\frac{1}{L_{j k}}\right)
$$

The first part of equation (4.2') consists of three parameters. Intuitively, these elements have an impact on the profitability of adjustments instead of the optimal size of the work force. That is, these elements have an impact on the difference between the revenues and the costs of adjusting the work force. The more profitable these adjustments are, the faster these adjustments will be. The parameter $a_{g k}$ indicates the size of the adjustment costs. The higher this parameter (that is, the higher the adjustment costs), the less profitable the adjustments are. The second element is the discount rate $r$. The higher the discount rate, the less future profits are rewarded by the firms, which implies that adjustments are rewarded less. Thirdly, the voluntary quit rate $\delta_{i j k}$. The higher the quit rate, the less involuntary adjustments are needed. This implies that adjustments yield lower costs.

The second part consists of four parameters determining the optimal educational structure of the work force directly. The first parameter is the shadow price $\lambda_{j k}$ of a unit of occupational output $y_{j k}$. This shadow price indicates the value of the contribution of an occupation to industrial output. The more useful a particular occupation $j$ in an industry $k$ is, the higher employment of type of education $i$ in occupation $j$ in industry $k$ will be, ceteris paribus. The second parameter $\gamma_{j k}$ stems from the occupational production function. The higher this parameter, the more important type of education $i$ is in the production delivered by occupation $j$ and the higher the share of this type of education will be, ceteris paribus. Thirdly, $\theta_{i j k}$, measuring the productivity of the type of education concerned. ${ }^{21}$ The higher the productivity, the higher the share in labour demand of the type of education concerned. In the fourth place, the wage. Not surprisingly, the higher the wage $w_{i}$, the lower the share of the type of education $i$ in labour demand. Finally, the third part is total labour demand in the occupation and industry concerned, which occurs to obtain the optimal share of type of education $i$ instead of employment in absolute numbers.

Combining the equations (4.1") and (4.2') yields the following labour demand function:

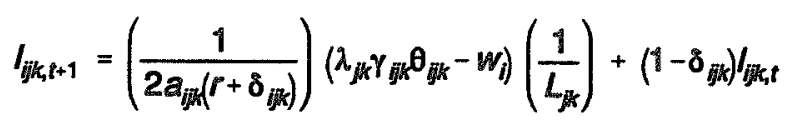

To summarise, this labour demand function shows that the higher the voluntary quit rate $\delta_{j k}$, the lower the discount rate $r$ and the higher the adjustment costs indicated by $a_{i j k}$, the faster labour demand is adjusted. Furthermore, equation (4.3) shows that the higher the occupational shadow price $\lambda_{j k}$, the higher the technological parameters $\gamma_{j k}$ and $\theta_{j j k}$ and the lower the wage rate $w_{i}$, the larger the adjustments in labour demand will be. 


\section{CONCLUSIONS}

Today's manpower forecasting models for a great deal lack an economic foundation. Current manpower forecasting practice heavily relies on trend extrapolation methods for reasons of simplicity and data limitations. In this paper an attempt is made to introduce adjustment costs into a manpower forecasting model. The aim was to find a way to take phenomena like labour hoarding and habit formation into account by forecasting the occupational and educational structure of labour demand.

The analysis in this paper results into a labour demand function in which future labour demand by type of education within an occupation and an industry is a weighted mean of current demand and the long run optimal level. The parameters determining labour demand by education can be divided into two groups. The first group consists of parameters which affect the speed of labour demand adjustments. These parameters are an adjustment cost parameter, the discount rate and the voluntary quit rate. The second group consists of parameters having an impact on the size of the optimal long run demand. These parameters are the shadow price of a unit of occupational production, the wage level and two technological parameters. One of these technological parameters originates from the occupational production function.

Unfortunately, the labour demand function derived in this paper can not be tested empirically. From a practical point of view, the labour demand function raises two problems. Firstly, determining the technological parameters, especially the parameters originating from the occupational production function. In the second place, measuring the shadow price of a unit of occupational production. The first problem is not only a practical one. It also has theoretical aspects. Determining the production function parameters implies determining the perfect match between demand and supply. In other words: determining which types of education are most suitable to fill a particular occupation. The aim of a subsequent paper will be to find solutions for these theoretical and practical problems and to investigate the reliability of the model. 


\section{REFERENCES}

De Koning, J. (1987), Omvang en Oorzaken van Labour Hoarding, Dissertation, Rotterdam.

Gould, J.P. (1968), 'Adjustments Costs in the Theory of Investment of the Firm', Review of Economic Studies, vol. 35, pp. 47-55.

Hamermesh, D.S. (1993a), Labor Demand, Princeton University Press, Princeton, New Jersey.

Hamermesh, D.S. (1993b), Labor Demand and the Source of Adjustment Costs, NBER Working Paper No. 4394, Cambridge MA.

Heijke, H. (ed) (1994), Forecasting the Labour Market by Occupation and Education, Kluwer Academic Publishers, Boston, Dordrecht, London.

Holt C., Modigliani, F., Muth, J. and Simon, H. (1960), Planning Production, Inventories and the Work Force, Prentince-Hall, Englewood Cliffs, New Jersey.

Hughes G. (1993), Projecting the Occupational Structure of Employment in OECD Countries, OECD Labour Market and Social Policy Occasional Papers nr. 10, OECD, Paris.

Nadiri, M.I. and Rosen, S. (1973), A Disequilibrium Model of Production, National Bureau of Economic Research, New York.

Nickell, S.J. (1986), 'Dynamic Models of Labour Demand', in: Ashenfelter, O. and Layard, R. (eds), Handbook of Labor Economics, volume 1, North Holland, Amsterdam, New York, Oxford, Tokyo.

Oi, W. (1962), 'Labor as a Quasi-Fixed Factor of Production', Joumal of Political Economy, vol. 70, pp. 538-555.

Pfann, G.A. (1989), Stochastic Adjustment Models of Labour Demand, Dissertation, Maastricht.

Van Eijs, P. and Borghans, L. (1993), Manpower Forecasting and the Aggregation Problem: a Microeconomic Approach, ROA-RM-1993/6E, Maastricht.

Van Eijs, P. (1994), Manpower Forecasting in the Western World: the Current State of the Art, ROA-RM1994/1E, Maastricht.

Van Ophem, H. and Hartog, J. (1993), 'Towards Disentangling Supply and Demand in a Model of Wages and Job Level', in: Van Ours, J.C., Pfann, G.A. and Ridder, G. (eds), Labor Demand and Equilibrium Wage Formation, North Holland, Amsterdam, London, New York, Tokyo. 
APPENDIX 1. DERIVATION OF THE LABOUR DEMAND FUNCTION UNDER STATIC EXPECTATIONS

The model consists of five equations:

$$
\begin{aligned}
& \pi_{j k, 0}^{*}=\int_{t=0}^{\infty} \pi_{j, t} e^{-\pi t} d t \\
& \pi_{j k, t}=\lambda_{j k,} y_{j k, t}\left(L_{1 j k, p} L_{2 j k, t} L_{3 j k, t}, \ldots, L_{n j k, t}\right)-\sum_{i=1}^{n} w_{i} L_{j k, t} \\
& \text { - } A C\left(i_{1 k,, r} i_{2 j k, n} i_{3 j k, k} \ldots, i_{n j k, t}\right)
\end{aligned}
$$

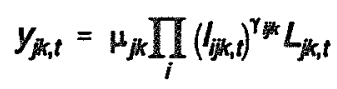

$$
\begin{aligned}
& L_{j k}=c_{j k} y_{j k} \\
& A C\left(i_{1 j k, r} i_{2 j k, p} i_{3 j k, p} \ldots, i_{n j k,}\right)=\sum_{i=1}^{n} a_{j k n}\left(i_{j k, t}+\delta I_{j k, t}\right)^{2} L_{j k}^{2}
\end{aligned}
$$

Substituting (A.2), (A.3) and (A.5) into (A.1) yields (A.6):

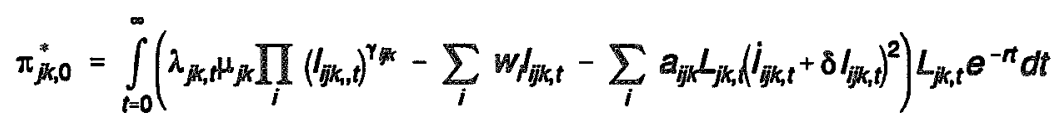

From this equation the time path of $I_{\text {g. }}$ can be derived. The first-order condition is:

$$
\int_{1}^{0} \pi_{j ;, 0}^{*} d t-\frac{d}{d t} \int_{1}^{0} \pi_{j k, 0}^{*} d t=0
$$

The two elements of this equation can be derived from (A.6):

$$
\int_{1}^{0} \pi_{j k, 0}^{*} d t=\left(\frac{\lambda_{j k, t} r_{j k} y_{j k, t}}{l_{j k, t}}-w_{i}-2 \delta_{j j k} a_{j k} L_{j k,}\left(i_{j k, t}+8 l_{j k, t}\right)^{2}\right) e^{-n}
$$

and:

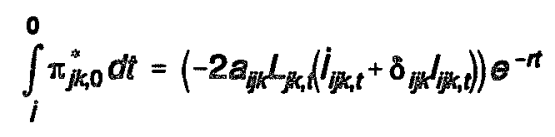

from which:

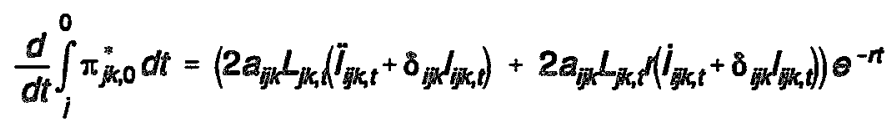

Now define:

$$
I N V_{g k, t}=\left(i_{g k, t}+\delta_{g k} l_{j k, t}\right) L_{j k, t}^{2}
$$

and, consequently: 


$$
I N V_{i j k, t}=\left(I_{j k, t}+\delta_{j j k} J_{i j k, t}\right) L_{j k, t}^{2}
$$

Substituting (A.8), (A.10), (A.11) and (A.12) into (A.7) and rearranging yields:

$$
I N V_{i j k, t}=\left(r+\delta_{j k k}\right) I N V_{i j k, t}+\frac{\left(\frac{\lambda_{j k, t} \gamma_{j k} y_{j k, t}}{l_{j k, t}}-w_{i}\right) L_{j k, t}}{2 a_{j k}}
$$

In the long run equilibrium $I N V_{y k}=0$. This implies that:

$$
I N V_{i k k}^{*}=\frac{\left(\frac{\lambda_{j k} \gamma_{j k} y_{j k}}{l_{j i k}}-w_{i}\right) L_{j k}}{2 a_{i j k}\left(r+\delta_{j k k}\right)}
$$

Furthermore, the following identities hold:

$$
I N V_{i j k}^{*}=\delta_{i j k} l_{i j k}^{*} L_{j k}^{2}
$$

and:

$$
I N V_{j k, t}=\left(i_{j k, t}+\delta_{j j k} I_{j k, t}\right) L_{j k, t}^{2}
$$

From (A.15) and (A.16), the following equation can be derived:

$$
i_{i k, t}=\delta_{i j k}\left(l_{j k}^{*}-l_{j k, t}\right)
$$

which is the same equation as (4.1). Furthermore, substituting (A.14) into (A.15) yields:

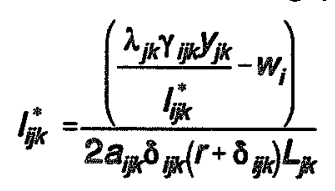

Because the production function (A.5) is assumed to be homogeneous of degree 1 and because (A.4) is supposed to hold:

$$
\frac{y_{j k}}{I_{j k}}=\theta_{j k}
$$

in which $\theta_{j k}$ is a technological (constant) parameter. Substituting (A.19) into (A.18) yields:

$$
I_{j k}^{*}=\frac{\lambda_{j k} \gamma_{j k} \theta_{i j k}-w_{i}}{2 a_{j k} \delta_{j k l} r+\delta_{j k k} L_{j k}}
$$

which is the same equation as (4.2). 
